\title{
Acute gastroenteritis in Hong Kong: a population-based telephone survey
}

\author{
S. C. $\mathrm{HO}^{1 *}$, P. H. CHAU ${ }^{2,3}$, P. K. FUNG ${ }^{2}$, A. SHAM ${ }^{4}$, E. A. $\mathrm{NELSON}^{5}$ AND J. SUNG \\ ${ }^{1}$ Department of Community and Family Medicine and Stanley Ho Centre for Emerging Infectious Diseases, \\ School of Public Health, The Chinese University of Hong Kong, HK \\ ${ }^{2}$ Stanley Ho Centre for Emerging Infectious Diseases, School of Public Health, The Chinese \\ University of Hong Kong, $H K$ \\ ${ }^{3}$ Faculty of Social Sciences, The University of Hong Kong, HK \\ ${ }^{4}$ Department of Community and Family Medicine, The Chinese University of Hong Kong, HK \\ ${ }^{5}$ Department of Paediatrics, The Chinese University of Hong Kong, HK \\ ${ }^{6}$ Department of Medicine and Therapeutics and Stanley Ho Centre for Emerging Infectious Diseases, The Chinese \\ University of Hong Kong, $\mathrm{HK}$
}

(Accepted 8 October 2009; first published online 20 November 2009)

\section{SUMMARY}

A population-based telephone survey of acute gastroenteritis (AG) was conducted in Hong Kong from August 2006 to July 2007. Study subjects were recruited through random digit-dialling with recruitments evenly distributed weekly over the 1-year period. In total, 3743 completed questionnaires were obtained. An AG episode is defined as diarrhoea $\geqslant 3$ times or any vomiting in a 24-h period during the 4 weeks prior to interview, in the absence of known non-infectious causes. The prevalence of AG reporting was 7\%. An overall rate of 0.91 (95\% CI 0.81-1.01) episodes per person-year was observed with women having a slightly higher rate $(0 \cdot 94$, $95 \%$ CI $0 \cdot 79-1 \cdot 08)$ than men $(0 \cdot 88,95 \%$ CI $0 \cdot 73-1 \cdot 04)$. The mean duration of illness was $3 \cdot 6$ days (s.D. $=5 \cdot 52$ ). Thirty-nine percent consulted a physician, $1.9 \%$ submitted a stool sample for testing, and $2 \cdot 6 \%$ were admitted to hospital. Of the subjects aged $\geqslant 15$ years, significantly more of those with AG reported eating raw oysters (OR 2·4, $95 \%$ CI 1·3-4.4), buffet meals (OR 1.8, $95 \%$ CI $1 \cdot 3-2 \cdot 5$ ), and partially cooked beef (OR 1.8, $95 \%$ CI $1 \cdot 2-2 \cdot 7$ ) in the previous 4 weeks compared to the subjects who did not report AG. AG subjects were also more likely to have had hot pot, salad, partially cooked or raw egg or fish, sushi, sashimi, and 'snacks bought at roadside' in the previous 4 weeks. This first population-based study on the disease burden of AG in Asia showed that the prevalence of AG in Hong Kong is comparable to that experienced in the West. The study also revealed some 'risky' eating practices that are more prevalent in those affected with AG.

Key words: Estimating, gastroenteritis, gastrointestinal infections, hygiene - food, infectious disease epidemiology, prevalence of disease.

\footnotetext{
* Author for correspondence: Professor S. C. Ho, School of Public Health and Primary Care, Chinese University of Hong Kong, 4th Floor, School of Public Health and Primary Care, Prince of Wales Hospital, Shatin NT, Hong Kong Special Administrative Region, China. (Email: suzanneho@cuhk.edu.hk)
} 


\section{INTRODUCTION}

Acute gastroenteritis (AG) is an important public health concern worldwide [1]. It is a common but largely preventable illness. The symptoms of AG include diarrhoea and/or vomiting, occasionally abdominal pain, cramps, and fever [2]. Modes of transmission for AG can be through food, water, person-to-person, as well as animal contacts [3-7]. Although AG is usually self-limiting, it can have severe consequences, particularly in the vulnerable groups such as children and the elderly. The medical and social costs associated with AG can be extensive [8]. In the USA, 211 million episodes of AG occur each year, resulting in $>0.9$ million hospitalizations and $>6000$ deaths [9]. Investigation of disease burden and risk factors have been extensively studied, based on laboratory confirmation and surveillance information [10, 11]. Several population-based studies of AG have been conducted in Western countries [12] such as UK [13], The Netherlands [14], Norway [2], Ireland [15], Australia [16], Malta [17], and USA [18]. However, studies on burden of AG in Asia have mainly been hospital-based [19], pathogen-specific [20], targeting children [21], or on clinical characteristics, disease trends or outbreak cases [22, 23]. Based on extrapolations from laboratory data and physician consultation, a recent study in Japan has estimated the incidences of foodborne infections from Campylobacter, Salmonella and V. parahaemolyticus to be 237, 32 and 15/100 000 per year, respectively [24]. In most localities, disease reporting is mainly based on statutory notifications or laboratory reporting. As only a small proportion of AG illness comes into contact with the formal health service [25], underreporting of enterics based on this information is a recognized problem $[11,26]$. We conducted the first population-based study in Hong Kong to investigate the disease burden of AG and also the types of risky behaviour more prevalent in those affected with AG. This is also the first such study conducted in Asia.

\section{METHODS}

\section{Study design and population}

The study was a territory-wide population-based retrospective telephone survey conducted over one year. A pilot study conducted in June 2006 consisting of 200 interviews provided an estimate of $6.6 \%$ AG prevalence [27]. A target sample size of 3700 subjects was planned according to the formula suggested by
Gauci et al. [17]. The study proper was conducted from 1 August 2006 to 31 July 2007. Subjects were recruited through random digit dialling with an even distribution of about 70 interviews conducted per week over the study period.

A modified random digit-dialling method was adopted. Telephone numbers were first selected by systematic sampling from the 2005 residential telephone directories. As some telephone numbers might not be listed in the directories, an expanded list was created. First, the last digit of the selected numbers were discarded, the numbers were appended with 0 to 9 to form the expanded list. A sample of numbers was selected from this expanded list by means of systematic sampling, and the final list contained 8335 listed numbers and 14590 unlisted numbers.

At least five attempts were made at different times (between 09:00 and 22:00 hours) of the day and on different days of the week (two weekdays and one weekend) before a phone number was considered as non-contactable. One member of the household, selected by the last birthday method [28], was interviewed over the telephone. Proxy (guidance) response was adopted if the selected subject was aged $<15$ years or physically and/or mentally unfit to respond to the questionnaire interview. The study was approved by the Survey and Behavioural Research Ethics Committee of The Chinese University of Hong Kong.

\section{Data collection}

The questionnaire was based on the validated questionnaire developed and used by members of the International Collaboration on Enteric Disease 'Burden of Illness' Studies [16, 18, 29] but modified to suit the local situation. The questionnaire was first developed in English and then translated into Cantonese and Mandarin. It was then pre-tested and further refined using 120 respondents randomly selected from the telephone directory.

The interviews were conducted by telephone by trained interviewers in Cantonese, Mandarin or English as appropriate. The structured questionnaire collected information on (i) the occurrence of diarrhoea or vomiting during the 4 weeks prior to interview; the presence of other household members with $\mathrm{AG}$; the duration of illness, the maximum number of diarrhoea and vomiting episodes during a 24-h period. The respondents were also asked to respond to a list of other symptoms which were AG-related including respiratory symptoms, coughing, sneezing, 
Table 1. Comparison of the distribution of the studied sample with the Hong Kong population*, by sex and age groups

\begin{tabular}{|c|c|c|c|c|c|c|}
\hline \multirow{2}{*}{$\begin{array}{l}\text { Age } \\
\text { groups } \\
\text { (yr) }\end{array}$} & \multicolumn{2}{|l|}{ Male } & \multicolumn{2}{|l|}{ Female } & \multicolumn{2}{|l|}{ Total } \\
\hline & $n$ & $\%$ & $n$ & $\%$ & $n$ & $\%$ \\
\hline \multicolumn{7}{|c|}{ Hong Kong population } \\
\hline $0-4$ & 110433 & $3 \cdot 4$ & 102172 & $2 \cdot 8$ & 212605 & $3 \cdot 1$ \\
\hline $5-14$ & 374118 & $11 \cdot 4$ & 352952 & $9 \cdot 8$ & 727070 & $10 \cdot 6$ \\
\hline $15-24$ & 448203 & $13 \cdot 7$ & 460802 & $12 \cdot 8$ & 909005 & $13 \cdot 3$ \\
\hline $25-44$ & 1015569 & $31 \cdot 0$ & 1285412 & $35 \cdot 8$ & 2300981 & $33 \cdot 5$ \\
\hline $45-64$ & 931221 & $28 \cdot 5$ & 930668 & $25 \cdot 9$ & 1861889 & $27 \cdot 1$ \\
\hline$\geqslant 65$ & 393412 & $12 \cdot 0$ & 459384 & $12 \cdot 8$ & 852796 & $12 \cdot 4$ \\
\hline Total & 3272956 & $100 \cdot 0$ & 3591390 & $100 \cdot 0$ & 6864346 & $100 \cdot 0$ \\
\hline \multicolumn{7}{|c|}{ Sample population } \\
\hline $0-4$ & 56 & $3 \cdot 4$ & 52 & $2 \cdot 5$ & 108 & $2 \cdot 9$ \\
\hline $5-14$ & 218 & $13 \cdot 4$ & 199 & $9 \cdot 5$ & 417 & $11 \cdot 2$ \\
\hline $15-24$ & 295 & $18 \cdot 1$ & 265 & $12 \cdot 7$ & 560 & $15 \cdot 1$ \\
\hline $25-44$ & 392 & $24 \cdot 0$ & 580 & $27 \cdot 8$ & 972 & $26 \cdot 2$ \\
\hline $45-64$ & 407 & $25 \cdot 0$ & 639 & $30 \cdot 6$ & 1046 & $28 \cdot 1$ \\
\hline$\geqslant 65$ & 262 & $16 \cdot 1$ & 352 & $16 \cdot 9$ & 614 & $16 \cdot 5$ \\
\hline Total & 1630 & $100 \cdot 0$ & 2087 & $100 \cdot 0$ & 3717 & $100 \cdot 0$ \\
\hline
\end{tabular}

No significant differences were found between the sample and the Hong Kong population for both sexes, and overall population.

* Source: 2006 by-census, Census \& Statistics Department, Government of HKSAR [32].

runny nose, sputum and nasal congestion. A subject would only be considered as having an AG-related respiratory symptom if they confirmed this in a follow-up question: self-interpretation on the cause of illness and, if food related, the food believed to have caused the illness, (ii) the use of medication, medical consultation sought, admission to hospital and whether a stool sample was sent for diagnostic purposes; (iii) practice of hand washing before meals, and questions which aimed to examine 'risky' food behaviours in the previous 4 weeks; meal types or food habits (takeaway foods, leftover foods, buffet meal, hot pot, self-grilled foods, poon choi , snacks bought at the roadside); consumption of food items (ice-cream, salad, sushi, sashimi, oyster) and other selected food items and their degree of doneness when consumed (fish, egg, beef, chicken, oyster, shrimp, crab, clam, etc.; and (iv) demographic characteristics.

\section{Definition of AG}

The symptom-based definition of AG, as suggested by Majowicz et al. [30], was adopted for this study. AG

$\dagger$ A traditional Chinese combination dish with layers of foods in a large serving pot. was defined as $\geqslant 3$ loose stools or any vomiting in any 24-h period. Vomiting or diarrhoea due to non-infectious causes such as Crohn's disease, ulcerative colitis, irritable bowel syndrome, excess alcohol, pregnancy, menstruation or medication was excluded. AG respondents with chronic gastroenteritis who experienced infectious AG over the previous 4 weeks were included as AG cases [29]. Respondents with conditions not meeting the definition of AG were considered as non-cases. Only the last episode of AG was considered [29], using the most conservative approach for the estimation of disease burden.

\section{Data analysis}

The prevalence of $A G$ in the 4 weeks prior to interview was calculated based on the defined AG cases $(n=262)$ and the total number of respondents $(n=$ 3743); while the incidence per person-year was calculated by multiplying the prevalence rate by 13 , as the number of 4-week periods in a year is $13.03(365 / 28)$. The prevalence of AG in the Hong Kong population was estimated with adjustment made for age, sex and residential district according to the 2006 Population by-census (Table 1) [31]. $\chi^{2}$ and $t$ tests were used for testing the association between socio-demographic 
Table 2. Prevalence of reporting acute gastroenteritis $(A G)$ in the 4 weeks prior to interview in the different socio-demographic groups of the study population

\begin{tabular}{|c|c|c|c|}
\hline & $\begin{array}{l}\text { No. in } \\
\text { group }\end{array}$ & $\%$ & $95 \% \mathrm{CI}$ \\
\hline $\begin{array}{l}\text { Prevalence in the } 4 \text { weeks } \\
\text { prior to interview }\end{array}$ & 3743 & $7 \cdot 0$ & $6 \cdot 2-7 \cdot 8$ \\
\hline \multicolumn{4}{|l|}{ Sex } \\
\hline Male & 1635 & $6 \cdot 8$ & $5 \cdot 6-8 \cdot 0$ \\
\hline Female & 2108 & $7 \cdot 2$ & $6 \cdot 1-8 \cdot 3$ \\
\hline \multicolumn{4}{|l|}{ Age groups $(y r) * *$} \\
\hline$<5$ & 108 & $11 \cdot 1$ & $5 \cdot 1-17 \cdot 1$ \\
\hline $5-14$ & 417 & $6 \cdot 2$ & $3 \cdot 9-8 \cdot 6$ \\
\hline $15-24$ & 560 & $9 \cdot 8$ & $7 \cdot 4-12 \cdot 3$ \\
\hline $25-44$ & 972 & $8 \cdot 0$ & $6 \cdot 3-9 \cdot 7$ \\
\hline $45-64$ & 1046 & $6 \cdot 4$ & $4 \cdot 9-7 \cdot 9$ \\
\hline$\geqslant 65$ & 614 & $3 \cdot 9$ & $2 \cdot 4-5 \cdot 5$ \\
\hline \multicolumn{4}{|l|}{$\begin{array}{l}\text { Education level of } \\
\text { those age } \geqslant 15 \text { years* }\end{array}$} \\
\hline No formal schooling & 204 & $4 \cdot 4$ & $4 \cdot 4-9 \cdot 9$ \\
\hline Primary & 534 & $4 \cdot 3$ & $3 \cdot 6-6 \cdot 7$ \\
\hline Secondary & 1457 & $7 \cdot 5$ & $5 \cdot 9-8 \cdot 5$ \\
\hline Matriculation and above & 969 & $8 \cdot 5$ & $6 \cdot 6-10 \cdot 1$ \\
\hline \multicolumn{4}{|l|}{ Household income (HK\$) } \\
\hline Low $(<15000)$ & 1066 & $6 \cdot 6$ & $5 \cdot 1-8 \cdot 1$ \\
\hline Medium (15000-30 000) & 953 & $8 \cdot 4$ & $6 \cdot 6-10 \cdot 2$ \\
\hline High $(\geqslant 30000)$ & 709 & $9 \cdot 5$ & $7 \cdot 3-11 \cdot 6$ \\
\hline
\end{tabular}

CI, Confidence interval.

$* p<0 \cdot 01, * * p<0 \cdot 001$ by $\chi^{2}$ test comparing AG prevalences in different categories.

Figures in bold denote statistical significance.

factors and the occurrence of AG. Logistic regression analysis was used for the estimation of risky behaviours associated with AG. Data were analysed using SPSS 13.0 (SPSS Inc., USA).

\section{RESULTS}

\section{Response rate and study sample}

The overall response rate was $41 \%$ with 3743 completed and 237 partially completed interviews. The incomplete questionnaires were excluded from analysis. The age distribution of the study participants and the general population was similar. Although the study sample had a slightly higher prevalence of females, the gender distribution was not significantly different from that of the general population (Table 1).

Of the completed interviews, 673 were conducted by proxy: 586 for those aged $\leqslant 15$ years and 87 for those with physical, mental or language difficulties in responding to the interview. In total, 482 experienced AG in the 4 weeks prior to interview. Of these, 44 experienced chronic gastroenteritis due to medication or medically confirmed chronic illnesses and two had pregnancy-induced vomiting. A total of 174 had $\geqslant 2$ episodes of diarrhoea within a 24 -h period and were not considered as AG cases. Respondents $(n=262)$ with episodes meeting the case definition were considered as having AG in the reporting period.

\section{Prevalence of AG}

An overall prevalence of $7 \cdot 0 \%$ of $A G$ was found, with women having a higher prevalence than men (Table 2). Children aged $\leqslant 5$ years had the highest prevalence of AG while the older age group ( $\geqslant 65$ years) had the lowest prevalence. Respondents with higher education also tended to have a higher reporting of AG. Table 3 shows the distribution of AG by sex and age groups. An overall adjusted prevalence of $7 \cdot 3 \%$ was observed when weighting for age, sex and residential district according to 2006 Hong Kong by-census data was applied [32]. Age standardization to the 2005 world population [31] resulted in a slightly higher prevalence of $7 \cdot 7 \%$.

\section{Disease burden}

The rate of AG episodes per person-year was estimated as $0.91(95 \%$ CI $0 \cdot 81-1 \cdot 01)$ (Table 4). Based on a similar AG case definition and method of estimation [30], the incidence of AG in Hong Kong (0.84) is similar to that of the USA, Canada and Australia while higher than that of Ireland (Fig. 1). The mean age of AG cases was $35 \cdot 2$ years (range 1-87), the mean duration of illness was 3.62 days (range $0.5-28$ ), while $16 \%$ still had symptoms at the time of interview (Table 4). The report of bloody diarrhoea was rare ( $2 \%$ ). Of AG cases, $8.8 \%$ also reported respiratory symptoms which included coughing, sneezing, sore throat, runny nose, sputum and nasal congestion. Thirty-nine percent consulted a physician but only $2 \%$ submitted a stool sample for testing. Of AG cases, $58 \%$ used medication, of which $14 \%$ took antibiotics and $55 \%$ antidiarrhoeal medicine; of the seven $(2.6 \%)$ admitted to hospital, three were aged $<10$ years, one in the 15-19 years age group, and three were aged $\geqslant 65$ years. 
Table 3. Distribution of respondents and prevalence of acute gastrointestinal illness by sex and age groups in a 4-week period in a sample of the Hong Kong population $(n=3743)$, with age, sex and residential district weighted according to the 2006 Hong Kong population*

\begin{tabular}{|c|c|c|c|c|c|c|c|c|}
\hline \multirow{2}{*}{$\begin{array}{l}\text { Age } \\
(\mathrm{yr})\end{array}$} & \multicolumn{3}{|l|}{ Male } & \multicolumn{3}{|c|}{ Female } & \multicolumn{2}{|c|}{ Total } \\
\hline & No. & $\%$ & $95 \% \mathrm{CI}$ & No. & $\%$ & $95 \% \mathrm{CI}$ & $\%$ & $95 \% \mathrm{CI}$ \\
\hline $0-4$ & 56 & $10 \cdot 3$ & $2 \cdot 4-18 \cdot 3$ & 52 & $12 \cdot 6$ & $3 \cdot 9-21 \cdot 3$ & $11 \cdot 5$ & $5 \cdot 6-17 \cdot 3$ \\
\hline $5-14$ & 218 & $6 \cdot 8$ & $3 \cdot 3-10 \cdot 2$ & 199 & $5 \cdot 9$ & $2 \cdot 6-9 \cdot 3$ & $6 \cdot 4$ & $4 \cdot 0-8 \cdot 8$ \\
\hline $15-24$ & 295 & $9 \cdot 5$ & $5 \cdot 8-13 \cdot 2$ & 265 & $9 \cdot 9$ & $6 \cdot 2-13 \cdot 7$ & $9 \cdot 7$ & $7 \cdot 1-12 \cdot 4$ \\
\hline $25-44$ & 392 & $6 \cdot 8$ & $4 \cdot 7-8 \cdot 9$ & 580 & $9 \cdot 3$ & $7 \cdot 1-11 \cdot 5$ & $8 \cdot 2$ & $6 \cdot 6-9 \cdot 7$ \\
\hline $45-64$ & 407 & $5 \cdot 9$ & $3 \cdot 8-8 \cdot 0$ & 639 & $7 \cdot 4$ & $5 \cdot 2-9 \cdot 7$ & $6 \cdot 7$ & $5 \cdot 1-8 \cdot 2$ \\
\hline$\geqslant 65$ & 262 & $2 \cdot 1$ & $0 \cdot 1-4 \cdot 0$ & 352 & $4 \cdot 6$ & $2 \cdot 0-7 \cdot 2$ & $3 \cdot 4$ & $1 \cdot 8-5 \cdot 1$ \\
\hline Total & 1630 & $6 \cdot 5$ & $5 \cdot 3-7 \cdot 6$ & 2087 & $8 \cdot 1$ & $6 \cdot 8-9 \cdot 3$ & $7 \cdot 3$ & $6 \cdot 5-8 \cdot 1$ \\
\hline
\end{tabular}

CI, Confidence interval.

* Source: 2006 by-census, Census \& Statistics Department, Government of HKSAR [32].

$\dagger$ Twenty-six respondents with age missing.

Table 4. Epidemiology of acute gastroenteritis $(A G)$ under the standard case definition*

\begin{tabular}{|c|c|c|}
\hline \multicolumn{3}{|l|}{ Incidence } \\
\hline Incidence per person-year $(95 \% \mathrm{CI})$ & $0 \cdot 91(0 \cdot 81-1 \cdot 01)$ & \\
\hline Incidence per person-year in males $(95 \% \mathrm{CI})$ & $0 \cdot 88(0 \cdot 73-1 \cdot 04)$ & \\
\hline \multirow[t]{2}{*}{ Incidence per person-year in females $(95 \% \mathrm{CI})$} & $0 \cdot 94(0 \cdot 79-1 \cdot 08)$ & \\
\hline & Mean (s.D.) & Range \\
\hline \multicolumn{3}{|l|}{ Characteristics of AG cases $(n=262)$} \\
\hline Mean age of cases $(\mathrm{yr})$ & $35 \cdot 2(20 \cdot 28)$ & $1-87$ \\
\hline \multirow[t]{2}{*}{ Mean duration of illness (days) $\dagger$} & $3 \cdot 62(5 \cdot 52)$ & $0 \cdot 5-28$ \\
\hline & $n$ & $\%$ \\
\hline Cases with bloody diarrhoea & 5 & $1 \cdot 9$ \\
\hline Cases that saw physician & 103 & $39 \cdot 3$ \\
\hline Cases submitting a stool sample for testing & 5 & $1 \cdot 9$ \\
\hline Cases with respiratory symptomst & 23 & $8 \cdot 8$ \\
\hline $\begin{array}{l}\text { Cases with symptoms still ongoing } \\
\text { at time of interview§ }\end{array}$ & 43 & $16 \cdot 4$ \\
\hline Cases that reported taking antibiotics & 21 & $8 \cdot 1$ \\
\hline Cases that reported taking antidiarrhoeals & 83 & $32 \cdot 0$ \\
\hline Cases that reported taking any medication & 151 & $57 \cdot 6$ \\
\hline
\end{tabular}

CI, Confidence interval.

Incidence rates were calculated by multiplying the 4-week prevalence by 13 .

* Individuals not meeting the AG case definition were considered a non-case [case definition : $\geqslant 3$ loose stools, or any vomiting in $24 \mathrm{~h}$, excluding those $(a)$ with cancer of the bowel, irritable bowel syndrome, Crohn's disease, ulcerative colitis, cystic fibriosis, coeliac disease, or another chronic illness with symptoms of diarrhoea or vomiting, or $(b)$ who report their symptoms were due to drugs, alcohol, or pregnancy]. $\dagger$ Mean duration calculated by averaging the duration of illness for all cases, regardless of whether they were still ongoing at the time of data collection.

+ Coughing, sneezing, sore throat, running nose, sputum and nasal congestion.

$\S$ For retrospective studies. 


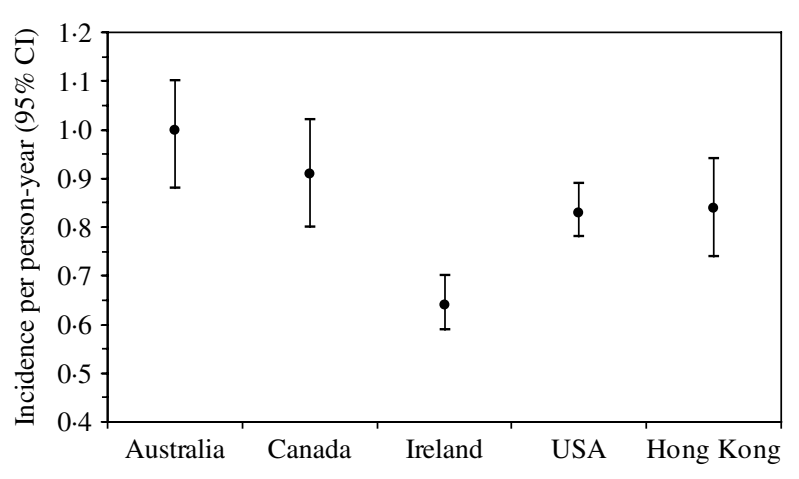

Fig. 1. Incidence and $95 \%$ confidence intervals of acute gastroenteritis using a similar standard case definition $\dagger$ in Australia, Canada, Ireland, USA and Hong Kong. († Standard case definition: $\geqslant 3$ loose stools, or any vomiting, in $24 \mathrm{~h}$, excluding those $(a)$ with cancer of the bowel, irritable bowel syndrome, Crohn's disease, ulcerative colitis, cystic fibriosis, coeliac disease, or another chronic illness with symptoms of diarrhoea or vomiting, or $(b)$ who report their symptoms were due to drugs, alcohol, or pregnancy. Individuals meeting the exclusion criteria were retained in the non-case group [30].) (The incidence rate in Hong Kong was calculated by multiplying the 4 -week prevalence by 12 , as in other countries, for ease of comparison.)

\section{Eating practices and AG}

Of the AG cases, $45 \%(118 / 262)$ believed that their AG could be food related. Of the 77 subjects who could recall the specific problematic food items, 39\% (30/77) thought it was due to seafood (oyster, shellfish, fish). The distribution of the other items was quite scattered, encompassing different types of meat, fruits and vegetables. Of the 77 cases, $45 \cdot 5 \%$ believed that the contaminated food source was from dining out, $10 \cdot 4 \%$ from takeaway foods, $9 \cdot 1 \%$ from buffets, and $15 \cdot 6 \%$ thought the source was from foods served at home.

A separate section of the structured questionnaire enquired about the food-eating practices and behaviour over the previous 4 weeks. Stratified analyses by age groups $(<15,15-44, \geqslant 45$ years) showed that for those aged $<15$ years, only salad eating had a significant and inverse association with AG (OR 0.29, $95 \%$ CI $0 \cdot 09-0 \cdot 95$ ). Table 5 shows the food or meal preferences found to be more prevalent in those with $\mathrm{AG}$ in the $\geqslant 15$ years age group. Some practices such as 'snacks bought at roadside', 'eating raw oysters', 'partially cooked/raw egg or fish' were more strongly and significantly associated with AG in those aged $\geqslant 45$ years than in the younger age groups (15-44 years). Overall, eating raw oysters (OR $2 \cdot 37,95 \% \mathrm{CI}$ $1 \cdot 29-4 \cdot 35$ ), partially cooked beef (OR $1 \cdot 82,95 \%$ CI
1.24-2.67) and buffet meals (OR 1.80, 95\% CI $1 \cdot 32-2 \cdot 46)$ seemed to be the strongest risk behaviour found in those with AG; followed by partially cooked/ raw egg, fish and self-grilled foods. Of those aged $\geqslant 65$ years, 'snacks bought at roadside' and 'eating partially cooked/raw eggs' were the only practices correlated with AG (data not shown). Only 5\% reported 'not washing hand before meals' and such practice was not found to be associated with AG. The presence of 'other family member(s) with AG' was significantly associated with an increased risk of AG (OR 3.03, 95\% CI 2.21-4·16).

\section{DISCUSSION}

A few population-based studies on the burden of AG have been conducted in different localities in the West [2, 13-18, 29] whereas this Hong Kong territory-wide survey is the first such study conducted in Asia. Using a similar symptom-based definition [15-18, 29, 30], the rate of AG in Hong Kong was 0.91 episode per person-year, which is similar to that observed in Australia, Canada, and the USA, but higher than that in Ireland and Malta $(0 \cdot 37,95 \%$ CI $0 \cdot 36-1 \cdot 89)$. The population-based study in Norway appears to indicate a higher AG rate $(9 \cdot 3 \%$ in the previous 4 weeks or 1.2 episodes per person-year), but it should be noted that the Norwegian study used a different case definition [2]. As in the other localities, women had a higher incidence of AG than men. The mean age ( 35.2 years) of subjects reporting AG and the mean duration of illness (3.62 days) were also comparable to that of other countries. However, the proportion of AG cases (39\%) that consulted a physician was relatively high compared to the range of $13 \%$ (Norway) to $39 \%$ (Malta) in other developed countries. Most countries share a low rate of submitting a stool sample for testing, ranging from $1.8 \%$ in Ireland, $1.9 \%$ in Hong Kong to $8 \%$ in Norway. The percentage of AG cases with respiratory symptoms $(8.8 \%)$ was lower than most other countries $(19 \cdot 2-47 \cdot 83 \%)$ probably because a follow-up question re-confirmed if the symptoms were AGrelated.

The highest prevalence of AG in children aged $<5$ years and the lowest in those aged $\geqslant 65$ years was consistent with reports from other populationbased studies [2, 14, 15, 18]. Rotavirus is a common cause of AG affecting mainly children, and globally almost every child has been infected with this pathogen at least once by age 5 years [33]. Although the 
Table 5. Association of eating practices in the previous 4 weeks of acute gastroenteritis (AG) reporting, by age groups for subjects aged $\geqslant 15$ years

\begin{tabular}{|c|c|c|c|c|c|c|c|}
\hline & \multicolumn{3}{|c|}{$15-44$ years $(n=1532)$} & \multicolumn{3}{|c|}{$\geqslant 45$ years $(n=1660)$} & \multirow{2}{*}{$\begin{array}{l}\text { Total }(n=3192) \\
\text { OR }(95 \% \text { CI })\end{array}$} \\
\hline & $n$ & $\mathrm{AG}(\%)$ & OR $(95 \% \mathrm{CI})$ & $n$ & $\mathrm{AG}(\%)$ & OR $(95 \% \mathrm{CI})$ & \\
\hline \multicolumn{8}{|l|}{ Takeaway food } \\
\hline No & 401 & $9 \cdot 0$ & $1 \cdot 00$ & 914 & $5 \cdot 0$ & $1 \cdot 00$ & $1 \cdot 00$ \\
\hline Yes & 1129 & $8 \cdot 6$ & $0 \cdot 95(0 \cdot 64-1 \cdot 42)$ & 744 & $6 \cdot 0$ & $1 \cdot 22(0 \cdot 80-1 \cdot 85)$ & $1.23(0.93-1.64)$ \\
\hline \multicolumn{8}{|c|}{ Snacks bought at roadside } \\
\hline No & 796 & $8 \cdot 8$ & $1 \cdot 00$ & 1473 & $5 \cdot 0$ & $1 \cdot 00$ & $1 \cdot 00$ \\
\hline Yes & 728 & $8 \cdot 5$ & $0.97(0.68-1 \cdot 38)$ & 183 & $9 \cdot 3$ & $1 \cdot 94(1 \cdot 12-3 \cdot 36)$ & $1 \cdot 40(1 \cdot 05-1 \cdot 87)$ \\
\hline \multicolumn{8}{|l|}{ Hot pot } \\
\hline No & 997 & $7 \cdot 9$ & $1 \cdot 00$ & 1366 & $5 \cdot 2$ & $1 \cdot 00$ & $1 \cdot 00$ \\
\hline Yes & 534 & $10 \cdot 1$ & $1 \cdot 31(0 \cdot 91-1 \cdot 88)$ & 293 & $6 \cdot 8$ & $1 \cdot 34(0 \cdot 80-2 \cdot 23)$ & $1 \cdot 45(1.08-1.94)$ \\
\hline \multicolumn{8}{|l|}{ Buffet } \\
\hline No & 1190 & $7 \cdot 8$ & $1 \cdot 00$ & 1436 & $4 \cdot 9$ & $1 \cdot 00$ & $1 \cdot 00$ \\
\hline Yes & 341 & $11 \cdot 4$ & $1 \cdot 52(1 \cdot 03-2 \cdot 26)$ & 223 & $9 \cdot 4$ & $2 \cdot 03(1 \cdot 22-3 \cdot 38)$ & $1 \cdot 80(1 \cdot 32-2 \cdot 46)$ \\
\hline \multicolumn{8}{|l|}{ Self-grilled food } \\
\hline No & 1225 & $8 \cdot 2$ & $1 \cdot 00$ & 1568 & $5 \cdot 4$ & $1 \cdot 00$ & $1 \cdot 00$ \\
\hline Yes & 305 & $10 \cdot 8$ & $1 \cdot 37(0 \cdot 90-2 \cdot 07)$ & 92 & $7 \cdot 6$ & $1 \cdot 46(0 \cdot 65-3 \cdot 24)$ & $1 \cdot 59(1 \cdot 11-2 \cdot 28)$ \\
\hline \multicolumn{8}{|l|}{ Salad } \\
\hline No & 903 & $7 \cdot 9$ & $1 \cdot 00$ & 1218 & $5 \cdot 3$ & $1 \cdot 00$ & $1 \cdot 00$ \\
\hline Yes & 628 & $9 \cdot 9$ & $1 \cdot 28(0 \cdot 90-1 \cdot 83)$ & 438 & $5 \cdot 7$ & $1.07(0.67-1.73)$ & $1 \cdot 30(1 \cdot 0-1 \cdot 72)$ \\
\hline \multicolumn{8}{|l|}{ Oyster } \\
\hline None & 1252 & $8 \cdot 4$ & $1 \cdot 00$ & 1406 & $5 \cdot 3$ & $1 \cdot 00$ & $1 \cdot 00$ \\
\hline Cooked/just cooked & 175 & $9 \cdot 7$ & $1 \cdot 21(0 \cdot 70-2 \cdot 07)$ & 198 & $4 \cdot 0$ & $0 \cdot 71(0 \cdot 34-1 \cdot 50)$ & $1 \cdot 00(0 \cdot 65-1 \cdot 53)$ \\
\hline Raw & 53 & $11 \cdot 3$ & $1 \cdot 49(0 \cdot 62-3 \cdot 58)$ & 36 & $19 \cdot 4$ & $3 \cdot 78(1 \cdot 58-9 \cdot 02)$ & $2 \cdot 37(1 \cdot 29-4 \cdot 35)$ \\
\hline \multicolumn{8}{|l|}{ Sushi } \\
\hline No & 688 & $7 \cdot 8$ & $1 \cdot 00$ & 1311 & $5 \cdot 2$ & $1 \cdot 00$ & $1 \cdot 00$ \\
\hline Yes & 841 & $9 \cdot 4$ & $1 \cdot 22(0 \cdot 85-1 \cdot 75)$ & 347 & $6 \cdot 3$ & $1 \cdot 24(0 \cdot 75-2 \cdot 03)$ & $1 \cdot 43(1 \cdot 09-1 \cdot 88)$ \\
\hline \multicolumn{8}{|l|}{ Sashimi } \\
\hline No & 774 & $8 \cdot 3$ & $1 \cdot 00$ & 1341 & $5 \cdot 0$ & $1 \cdot 00$ & $1 \cdot 00$ \\
\hline Yes & 757 & $9 \cdot 1$ & $1 \cdot 11(0 \cdot 78-1 \cdot 59)$ & 317 & $7 \cdot 3$ & $1.49(0.91-2 \cdot 43)$ & $1 \cdot 42(1 \cdot 08-1 \cdot 87)$ \\
\hline \multicolumn{8}{|l|}{ Fish } \\
\hline Cooked/just cooked & 725 & $7 \cdot 6$ & $1 \cdot 00$ & 1283 & $4 \cdot 6$ & $1 \cdot 00$ & $1 \cdot 00$ \\
\hline Others* & 734 & $9 \cdot 3$ & $1 \cdot 24(0 \cdot 86-1 \cdot 80)$ & 308 & $7 \cdot 5$ & $1 \cdot 67(1 \cdot 02-2 \cdot 76)$ & $1 \cdot 59(1 \cdot 19-2 \cdot 12)$ \\
\hline \multicolumn{8}{|l|}{ Beef } \\
\hline Cooked/just cooked & 986 & $7 \cdot 6$ & $1 \cdot 00$ & 900 & $4 \cdot 9$ & $1 \cdot 00$ & $1 \cdot 00$ \\
\hline Others* & 249 & $12 \cdot 9$ & $1 \cdot 79(1 \cdot 15-2 \cdot 78)$ & 99 & $6 \cdot 1$ & $1 \cdot 26(0 \cdot 52-3 \cdot 02)$ & $1 \cdot 82(1 \cdot 24-2 \cdot 67)$ \\
\hline \multicolumn{8}{|l|}{ Egg } \\
\hline Cooked/just cooked & 943 & $7 \cdot 7$ & $1 \cdot 00$ & 1216 & $4 \cdot 7$ & $1 \cdot 00$ & $1 \cdot 00$ \\
\hline Others* & 468 & $9 \cdot 6$ & $1 \cdot 27(0 \cdot 86-1 \cdot 87)$ & 233 & $8 \cdot 6$ & $1 \cdot 91(1 \cdot 12-3 \cdot 24)$ & $1 \cdot 60(1 \cdot 17-2 \cdot 18)$ \\
\hline
\end{tabular}

OR, Odds ratio; CI, confidence interval.

* Others included raw, half-cooked or a combination of both.

Figures in bold denote statistical significance.

elderly group has the lowest AG rate, they seem to share the largest disease burden in terms of hospitalization and mortality [34]. In the current study, three of the seven cases admitted to hospital for AG were in the elderly group. The lower AG rate observed in those aged $\geqslant 65$ years might be due to sampling bias as elderly individuals residing in nursing homes or hospitalized because of AG or other illnesses would not be captured by this survey [29]. The lower prevalence of risky behaviours might also partly explain the lower AG rates in the older population.

Eating seafood such as oysters or shellfish was the most commonly implicated cause of AG in those who believed their AG was caused by contaminated foods. About half also indicated a food source 'away from home'. 'Eating in restaurants' has also been found to 
be a risk factor for foodborne disease outbreaks in the USA [35]. However, information supplied in our study was based on subjective reporting and the AG pathogens have not been laboratory confirmed. Our study has also identified a higher prevalence of some 'risky' eating behaviours in subjects with AG compared to those not reporting AG in the previous 4 weeks, but a cause-effect relationship was not established. AG cases were more likely to have consumed raw oysters. Being a filter feeder, oysters can concentrate viruses from contaminated water [36]. A local study found that $10.5 \%$ of the imported raw oyster samples were positive for norovirus [23]. In an investigation of 13 outbreaks in which oyster was the implicated source of infection, norovirus was detected from at least one patient in all of the outbreaks and found in at least one oyster in six of these outbreaks [23].

In our study, AG cases were twice as likely to have had buffet meals in the previous 4 weeks compared to non-AG subjects. Improper food storage, heating or handling can result in food contamination, with the proliferation of bacteria/viruses and accumulation of toxins causing AG [37]. The situation is particularly risky when large batches of foods like buffet meals are served. Buffet meals have become quite popular in Hong Kong in recent years, particularly during holidays and festivals. A number of food-poisoning outbreaks related to buffet meals have been reported $[38,39]$. Even buffets served in prestigious hotels have been found to be related to food-poisoning outbreaks $[39,40]$.

More of the AG cases reported having had selfgrilled foods, hot pot, partially cooked or raw beef, fish and eggs in the previous 4 weeks compared to the non-AG subjects. Cross-contamination of raw and cooked foods and consumption of inadequately cooked foods are common during barbecues, or eating in restaurants where raw meats and foods are served in room temperature for self-grilling [41, 42]. Similarly, 'hot pot' is a traditional Chinese eating practice where mostly raw foods are served for selfcooking, with foods that are just cooked or partially cooked frequently preferred. Egg is well-known for Salmonella contamination [43]. Raw or partially cooked egg is commonly served in some Hong Kong dishes such as beef rice, congee and hot pot. The situation can be risky in a temperate climate like Hong Kong, where pathogens can multiply quickly in foods.

The Japanese-style sashimi and sushi have become popular foods in Hong Kong, especially among the young. Inadequate hygienic preparation and storage of these foods are of concern. A recent survey by the Hong Kong Consumer Council revealed an excessive level of pathogens like Staphylococcus aureus and Escherichia coli in these foods served in some eating premises [44]. Salad has also been reported to cause large-scale outbreaks in other populations [45]. Of those aged $\geqslant 15$ years, marginally more AG cases than non-AG cases reported 'eating salad' in the previous 4 weeks. As most of the ingredients in salad are eaten raw, cross-contamination of foods and being left out in room temperature for long periods could increase the risk of AG [46]. Roadside eating is relatively inexpensive and is still a common practice in Hong Kong, but the hygienic conditions of food preparation by the unlicensed hawkers can be questionable [47]. With the fast pace of life in Hong Kong, eating out is increasingly common, and certain popular foods can be risky. The higher prevalences of AG in those with higher education could also be related to their food or meal preferences.

Besides consumption of risky food items, personal hygiene is another concern regarding the cause of AG. A systematic review of intervention trials (2003) [48] revealed 'not washing hands with soap' was associated with diarrhoeal diseases, with a pooled relative risk of 1.88 (95\% CI 1.31-2.68). In our study, $95 \%$ reported 'washing hands before meal' but the quality of hand washing, such as the duration and use of disinfectant, was not investigated. The universal use of chopsticks by the Chinese when having meals may partly explain the lack of association between 'hand washing' and AG risk.

This 1-year telephone survey has estimated the AG rates in Hong Kong and revealed a number of risky behaviours in those affected by AG. The current study has several limitations. The AG cases were defined based on self-reported symptoms without laboratory confirmation but similar symptom-based case definition has been adopted in other population-based studies, so inter-population comparison is possible. The occurrence of AG was based on retrospective recall of events in the previous 4 weeks which is a rather long period. Bias due to the telescoping effect of some past illnesses may lead to an overestimation of the incidence of AG [29], although we tried to minimize such bias by referring to the exact calendar dates as the observation period. Our response rate of $41 \%$ is comparable to that obtained in previous telephone surveys with rates ranging from $27 \%$ to $71 \%$ [29]. Not possessing a telephone line by some households 
and a possible tendency for home-workers to respond to the interview (claiming to be the person with the last birthday) might affect the representativeness of the study population. Ninety-five percent of Hong Kong households have a telephone line [49], and every attempt was made to contact the selected respondent at a time that was convenient to them. The age and sex distribution in the study sample is quite comparable to that of the Hong Kong general population [32]. Because of the comprehensiveness of the questionnaire, each interview lasted about 15 min resulting in some incomplete questionnaires. 'Being busy' was the main cause of refusals although we offered to call back at a time more convenient to the respondent. The possibility of inaccurate answers provided by the proxy respondents for subjects aged $\leqslant 15$ years might be another drawback.

A number of eating or meal preferences were found to be more prevalent in subjects affected with AG. Because of the cross-sectional design and retrospective recall of events in the previous 4 weeks, no temporal or cause-effect relationships can be drawn from these associations. Although 'risky' foods and behaviours were enquired about in a separate section of the questionnaire (not immediately following the symptom questions), being aware of the 'risky' foods or eating practices possibly leading to $A G$ might increase the respondents' tendency to report these items.

Despite these potential limitations, this is the first territory-wide study on the disease burden of AG in Asia. Based on the common, symptom-based case definition, our results reveal that the incidence and distribution pattern of AG in Hong Kong are similar to those observed in Western populations. This study has also highlighted some potential food or meal preferences associated with AG. These findings indicate a strong need for promotion of food hygiene and the exercise of caution in the consumption of some potentially risky foods or meal types.

\section{ACKNOWLEDGEMENTS}

This study was supported by Food and Health Bureau through the Research Fund for the Control of Infectious Diseases.

\section{DECLARATION OF INTEREST}

None.

\section{REFERENCES}

1. Kosek M, Bern C, Guerrant RL. The global burden of diarrhoeal disease, as estimated from studies published between 1992 and 2000. Bulletin of the World Health Organization $2003 ; 81$ : 197-204.

2. Kuusi M, et al. Incidence of gastroenteritis in Norway - a population-based survey. Epidemiology and Infection 2003; 131: 591-597.

3. Mitakakis TZ, et al. Dietary intake and domestic food preparation and handling as risk factors for gastroenteritis: a case-control study. Epidemiology and Infection 2004; 132: 601-606.

4. Kuusi M, et al. A prolonged outbreak of Norwalk-like calicivirus (NLV) gastroenteritis in a rehabilitation centre due to environmental contamination. Epidemiology and Infection 2002 ; 129: 133-138.

5. Evans MR, et al. An outbreak of viral gastroenteritis following environmental contamination at a concert hall. Epidemiology and Infection 2002; 129: 355-360.

6. Nygard K, et al. Waterborne outbreak of gastroenteritis in a religious summer camp in Norway, 2002. Epidemiology and Infection 2004; 132: 223-229.

7. Caprioli A, et al. Enteropathogens associated with childhood diarrhea in Italy. The Italian Study Group on Gastrointestinal Infections. Pediatric Infectious Diseases Journal 1996; 15: 876-883.

8. Smith JL. Arthritis, Guillain-Barré syndrome, and other sequelae of Campylobacter jejuni enteritis. Journal of Food Protection 1995; 58: 1153-1170.

9. Mead PS, et al. Food-related illness and death in the United States. Emerging Infectious Diseases 1999; 5: 607-625.

10. Majowicz SE, et al. Estimating the under-reporting rate for infectious gastrointestinal illness in Ontario. Canadian Journal of Public Health 2005; 96: 178181.

11. Thomas MK, et al. Estimated numbers of community cases of illness due to Salmonella, Campylobacter and verotoxigenic Escherichia coli: pathogen-specific community rates. Canadian Journal of Infectious Diseases \& Medical Microbiology 2006; 17: 229-234.

12. Flint JA, et al. Estimating the burden of acute gastroenteritis, foodborne disease, and pathogens commonly transmitted by food: an international review. Clinical Infectious Diseases 2005; 41: 698-704.

13. Wheeler JG, et al. Study of infectious intestinal disease in England: rates in the community, presenting to general practice, and reported to national surveillance. The Infectious Intestinal Disease Study Executive. British Medical Journal 1999; 318: 1046-1050.

14. de Wit MA, et al. Sensor, a population-based cohort study on gastroenteritis in the Netherlands: incidence and etiology. American Journal of Epidemiology 2001; 154: 666-674.

15. Scallan E, et al. Acute gastroenteritis in Northern Ireland and the Republic of Ireland: a telephone survey. Communicable Disease and Public Health 2004; 7: 61-67. 
16. Hall G, et al. Estimating foodborne gastroenteritis, Australia. Emerging Infectious Diseases 2005; 11: 1257-1264.

17. Gauci C, et al. Challenges in identifying the methodology to estimate the prevalence of infectious intestinal disease in Malta. Epidemiology and Infection 2006; 134: 393-399.

18. Jones TF, et al. A population-based estimate of the substantial burden of diarrhoeal disease in the United States; FoodNet, 1996-2003. Epidemiology and Infection 2007; 135: 293-301.

19. Nakagomi T, et al. Incidence and burden of rotavirus gastroenteritis in Japan, as estimated from a prospective sentinel hospital study. Journal of Infectious Diseases 2005; 192 (Suppl. 1): S106-110.

20. Lee N, et al. Fecal viral concentration and diarrhea in norovirus gastroenteritis. Emerging Infectious Diseases 2007; 13: 1399-1401.

21. Lee WS, Poo MI, Nagaraj S. Estimates of economic burden of providing inpatient care in childhood rotavirus gastroenteritis from Malaysia. Journal of Paediatrics and Child Health 2007; 43: 818-825.

22. Tsang OT, et al. Clinical characteristics of nosocomial norovirus outbreaks in Hong Kong. Journal of Hospital Infection 2008; 69: 135-140.

23. Cheng PK, et al. Norovirus contamination found in oysters worldwide. Journal of Medical Virology 2005; 76: 593-597.

24. Kubota K, et al. The human health burden of foodborne infections caused by Campylobacter, Salmonella, and Vibrio parahaemolyticus in Miyagi Prefecture, Japan. Foodborne Pathogens and Disease 2008; 5: 641-648.

25. Scallan E, et al. Prevalence of diarrhoea in the community in Australia, Canada, Ireland, and the United States. International Journal of Epidemiology 2005; 34: 454-460.

26. Voetsch AC, et al. Analysis of the FoodNet case-control study of sporadic Salmonella serotype Enteritidis infections using persons infected with other Salmonella serotypes as the comparison group. Epidemiology and Infection 2009; 137: 408-416.

27. Ho SC, et al. A population-based study of burden of acute gastrointestinal illness in Hong Kong: report of the pilot study. WHO Consultation to Develop a Strategy for Estimating the Global Burden of Foodborne Diseases. Geneva: WHO, 2006.

28. Watson EK, et al. Conducting regional health surveys using a computer-assisted telephone interviewing method. Australian Journal of Public Health 1995; 19: 508-511.

29. Majowicz SE, et al. Magnitude and distribution of acute, self-reported gastrointestinal illness in a Canadian community. Epidemiology and Infection 2004; 132: 607-617.

30. Majowicz SE, et al. A common, symptom-based case definition for gastroenteritis. Epidemiology and Infection 2008; 136: 886-894.
31. World Bank. World population 2005 (http://go. worldbank.org/072F5QBOC0). Accessed December 2008.

32. Anon. 2006 by-census. Census \& Statistics Department. Government of HKSAR.

33. Velazquez FR, et al. Rotavirus infections in infants as protection against subsequent infections. New England Journal of Medicine 1996; 335: 1022-1028.

34. Herikstad $\mathbf{H}$, et al. A population-based estimate of the burden of diarrhoeal illness in the United States: FoodNet, 1996-1997. Epidemiology and Infection 2002; 129: 9-17.

35. Jones TF, Angulo FJ. Eating in restaurants: a risk factor for foodborne disease? Clinical Infectious Diseases 2006; 43: 1324-1328.

36. Rippey SR. Infectious diseases associated with molluscan shellfish consumption. Clinical Microbiology Reviews 1994; 7 : 419-425.

37. Altekruse SF, et al. Vibrio gastroenteritis in the US Gulf of Mexico region: the role of raw oysters. Epidemiology and Infection $2000 ; \mathbf{1 2 4}$ : 489-495.

38. Greig J, et al. An outbreak of Salmonella typhimurium phage type 99 linked to a hotel buffet in Victoria. Communicable Disease Intelligence 2001; 25 : 277-278.

39. de Wit MA, et al. Large outbreak of norovirus: the baker who should have known better. Journal of Infection 2007; 55: 188-193.

40. Mingpao 2008 (http://www.leedeelive.com/thread18772-1-1.html). Accessed December 2008.

41. Centre for Health Protection. The Hong Kong Government. Fact sheet on norovirus associated diarrhoea, 2006.

42. Mazick A, et al. An outbreak of Campylobacter jejuni associated with consumption of chicken, Copenhagen, 2005. Eurosurveillance 2006; 11: 137-139.

43. Gantois I, et al. Salmonella enterica serovar Enteritidis genes induced during oviduct colonization and egg contamination in laying hens. Applied and Environmental Microbiology 2008; 74: 6616-6622.

44. EpochTimes.com (http://news.epochtimes.com/b5/8/12/ 17/n2366114.htm). Accessed December 2008.

45. Schmid D, et al. A foodborne norovirus outbreak due to manually prepared salad, Austria 2006. Infection 2007; 35: 232-239.

46. Gallimore CI, et al. Detection of multiple enteric virus strains within a foodborne outbreak of gastroenteritis: an indication of the source of contamination. Epidemiology and Infection 2005; 133: 41-47.

47. Centre for Health Protection. Prevention of food poisoning. Department of Health. HKSAR (http://www. chp.gov.hk/files/pdf/grp-foodpois-en-2004052100.pdf). Accessed February 2009.

48. Curtis V, Cairncross S. Effect of washing hands with soap on diarrhoea risk in the community: a systematic review. Lancet Infectious Diseases 2003; 3: 275-281.

49. Anon. Office of the Telecommunications Authority. HKSAR. 